\title{
Content and Technology Based Pedagogy of Enriching Knowledge and Thinking Skills among Engineering Graduates
}

\author{
H. M. Naveen
}

Assistant Professor, Department of Mechanical Engineering, RYM Engineering College, Ballari, Karnataka, India

Article Info

Volume 7, Issue 5

Page Number: 28-34

Publication Issue :

September-October-2021

Article History

Accepted : 07 Sep 2021

Published : 14 Sep 2021

\section{ABSTRACT}

TPACK framework becomes an effective way to consider how teaches could incorporate educational technology into the classroom. It can also provide as a measurement for instructor knowledge, potentially impacting both training and professional development for teachers. This framework is helpful for the ways in which it explains the types of knowledge a teacher must need in order to integrate technology successful in the classroom.

Keywords : Technology, Knowledge, Pedagogy Knowledge, Content Knowledge

\section{INTRODUCTION}

In this digital era, technical innovations are integrated into all areas of human life. Technological developments give a rapid acceleration to engineering education also. For effective teaching-learning process a perfect balance between technological knowledge, pedagogical knowledge, and content knowledge is necessary. For this purpose, the framework called Technological Pedagogical Content Knowledge was developed as TPACK framework by Koehler and Mishra in 2005 based on Shulman's (1986) Pedagogical Content Knowledge strategy. Teacher's knowledge, skills and competencies are integrated with Technology in this model (Koehler and Mishra, 2005). In the present practice, technology is treated separately in teaching and learning process. Most of the time, the technocrats will think about the use of various educational software's and strategies for improving the learning outcome rather than about adopting them into classroom environment. But, Kabakci and Coklar (2014) emphasized that, in Technological Pedagogical content knowledge model, the teachers' content knowledge, their pedagogical competency and ability to use technology should be given in relation to each other rather than giving them as independent disciplines. The three prerequisites essential for implementation of this strategy are : first, teachers need strong knowledge base about the content area ; second teachers must understand the pedagogical knowledge required to create a constructivist learning environment ; lastly, teachers need strong technological knowledge. Thus, TPACK equip the teachers to integrate technologies in classroom teaching. 


\section{THEORETICAL VIEW}

The theoretical framework Technological Pedagogical Content Knowledge (TPCK) was first introduced to the field of educational practice by (Mishra and Koehler, 2006). Later, it was made popular as TPACK to form a more integrated whole for the three kinds of knowledge - technology pedagogy and content (Thompson and Mishra, 2008). This framework was built on Shulman's construct of Pedagogical Content Knowledge (PCK) with a view to include technological knowledge as part of content and pedagogical knowledge. TPACK strategy introduces the relationships and complexities between the three basic components of knowledge - technology, pedagogy, and content (Koehler and Mishra, 2008). It focus on the essential knowledge a teacher must have in order to integrate technology in their pedagogical practices. This approach conserves the characteristics of constructivism and gives importance to 'experience' as part of learning and doing. It is a student centered approach in teaching learning process with more of student participation. Group activities are also advocated to seek student attention and to promote active learning. It will also promote the use of cognitive tools to achieve success in the future (Mishra, 2018).

The TPACK framework goes beyond the mere observation of the three basic knowledge constructs Content, Pedagogy and Technology. The TPACK approach goes further by emphasizing the types of knowledge created at the intersections of three primary forms, as well as, looking at these three knowledge bases in isolation. These new knowledge domains are :

$\begin{array}{lccc}\text { Pedagogical } & \text { Content } & \text { Knowledge } & \text { (PCK), } \\ \text { Technological } & \text { Content } & \text { Knowledge } & \text { (TCK), }\end{array}$ Technological Pedagogical Knowledge (TPK), and Technological Pedagogical Content Knowledge (TPACK). The following diagram depict the organization of these three basic knowledge domains into four areas of knowledge structures as predicted by Mishra and Koehler (2009).

Figure - 1 : Technological Pedagogical Content Knowledge Framework by Mishra and Koehler (2009)

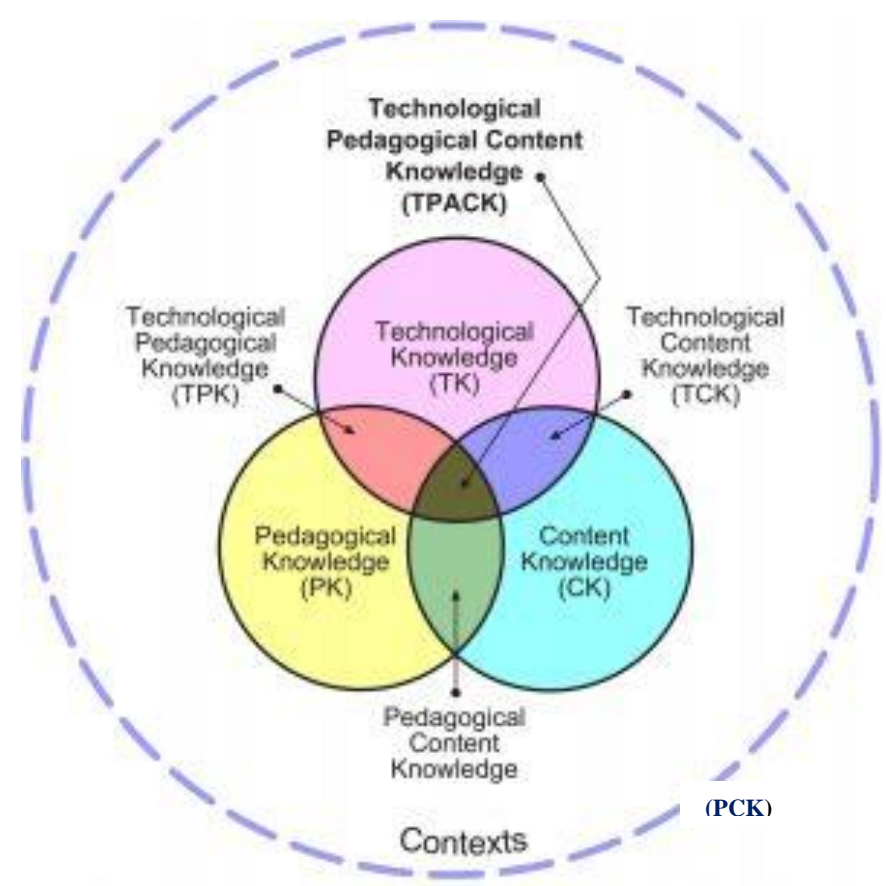

The Seven Components of TPACK

i. Content Knowledge (CK)

This first knowledge domain refers to the teachers' knowledge about the subject matter that is to be taught. It would include knowledge of concepts, theories, ideas, organizational frameworks, knowledge of evidence and poof, as well as established practices and approaches towards developing such knowledge (Koehler and Mishra, 2009).

ii. Pedagogical Knowledge (PK)

The second knowledge domain refers to the teachers' deep knowledge about the methods and processes of teaching and learning. It includes the fundamental knowledge in theories, practices, and methodologies that guide teaching-learning processes. It also consists of the awareness about classroom management, lesson plan development, student learning and assessment (Koehler and Mishra, 2009). 


\section{iii. Technology Knowledge (TK)}

The third sub domain refers to the knowledge of some ways of thinking and working with technology. This includes the sufficient understanding about information technology and how to apply it productively at work and in everyday life. It also includes the ability to recognize when this technology can help or prevent the achievement of a goal and to be able to continually adapt to changes in information technology (Koehler and Mishra, 2009).

iv. Pedagogical Content Knowledge (PCK)

This sub domain is similar to Shulman's idea of knowledge of pedagogy applicable to teaching of specific content. According to Shulman (1986), when the teacher interprets the topic, the finds different ways to represent it and adapts and prepares teaching materials for alternative topics. It covers the core business of teaching, learning, curriculum, assessment and reporting, as well as, conditions that promote learning and the links between curriculum, assessment and pedagogy (Koehler and Mishra, 2009).

v. Technological Content Knowledge (TCK)

It refers to an understanding of how technology and content influence and limit each other. Teachers need mastery over the subject matter they teach, and also an insight into how the subject matter can be changed through the application of particular technologies. Teachers need to understand which specific technologies are best suited to address a particular learning problem ; and how content imposes or perhaps changes technology or vice versa (Koehler and Mishra, 2009).

\section{vi. Technological Pedagogical Knowledge (TPK)}

The sixth sub domain refers to the knowledge of how teaching and learning can change when certain technologies are used in particular ways. This includes knowledge of the pedagogical possibilities, and limitations of a variety of technological tools related to disciplinarily and developmentally appropriate pedagogical designs and strategies (Koehler and Mishra, 2009). vii. Technological Pedagogical Content Knowledge (TPACK)

The final sub component TPACK is different from knowledge of all the three concepts. Infact, it is the foundation of an effective use of technology in teaching, which demands an understanding of the representation of concepts using technologies ; pedagogical techniques that use technologies in a constructive way to teach content; knowledge of what makes concepts difficult or easy to learn ; and how technology can assist to correct some of the problems students face. It needs an understanding of students' prior knowledge, theories of epistemology, and knowledge of how use of technologies can help to develop existing knowledge or strengthen the old ones (Koehler and Mishra, 2009).

\section{REVISED VERSION OF TPACK FRAMEWORK}

The TPACK framework describes the different types of knowledge required by teachers for successful addition of technology in teaching. It has a strong influence on research and practice in professional courses like Engineering Education. This framework is mainly distinguished by the TPACK diagram three interlocking circles (TK, CK, and PK) with an outer dotted circle (context). This image has remained unchanged since 2009. However, Mishra argued that there is a semantic contradiction in this highly reproduced, canonical image of TPACK. This contradiction implies what an enclosed space in the diagram. The three overlapping circles in the center of the diagram symbolize different aspects of teachers' knowledge - the knowledge in TK, PK and CK. The outer dotted circle encloses a space, but it is not considered as a form of knowledge. It is labelled as Context or Contexts.

In order to overcome this confusion, the name of the outer dashed circle is labelled as 'Contextual Knowledge' (i.e., teachers' knowledge of the context). An added benefit of this renovation is, an outer circle 
is considered as an another domain of knowledge that teachers must possess in order to integrate technology into teaching. Thus, it is clear that teachers must also work to increase their contextual awareness.

The contextual knowledge is labelled as $\mathrm{XK}$ for 'conteXtual Knowledge' distinguishing it from CK. Additionally, using $\mathrm{X}$ for conteXtual could be appropriate because $\mathrm{X}$ usually denotes a variable, and contextual knowledge often is highly variable. The incorporation of XK into the diagram highlights the teacher's organizational and situational restrictions in which they work. The success depends not only on their knowledge of T, P, C and its interaction, but also on their contextual knowledge. This leads the educational planners to consider teachers as the curriculum planners in their classrooms. Perfect connection between 'technology implementation' and 'pedagogical decisions' is essential for teaching and learning that desires to move toward transformation.

The following is the schematic representation of evolution of TPACK :

Figure - 2 : Schematic Representation of Evolution of TPACK

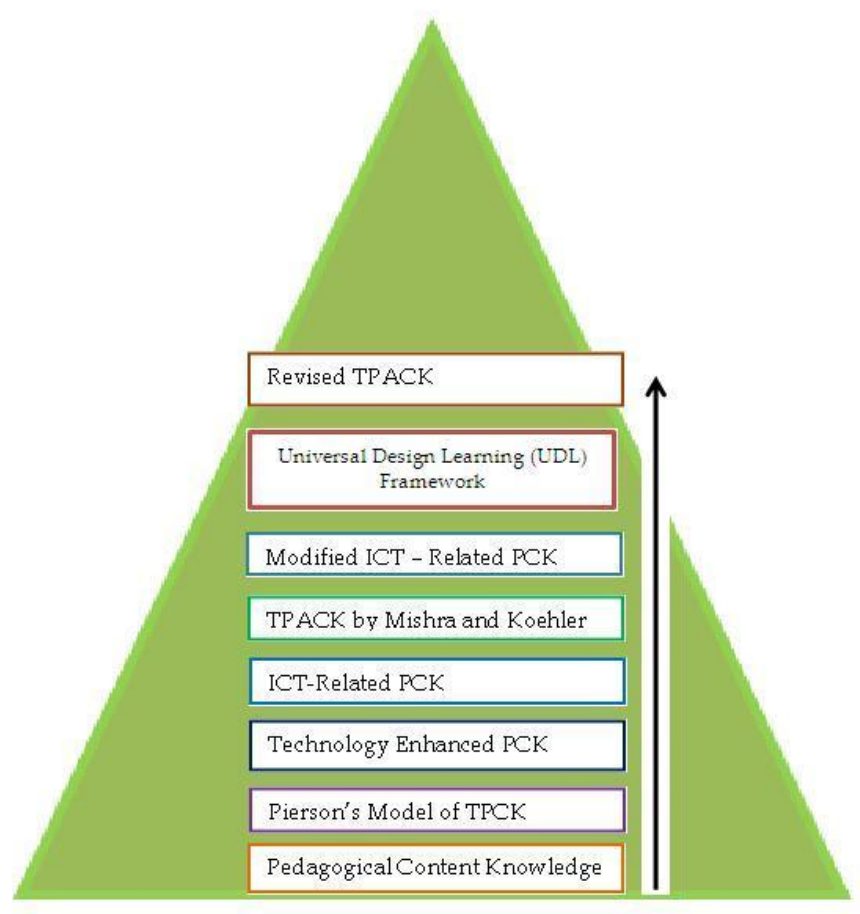

\section{DESIGN AND DEVELOPMENT OF TPACK BASED STRATEGY}

The TPACK framework is a perfect combination of content, pedagogy and technology which provide Engineering teachers with a comprehensive educational practice. In TPACK framework, technology does not replace pedagogical or content knowledge, it adds another dimension. In this framework, content knowledge, pedagogical knowledge and technological knowledge and complex interplay of these three bodies of knowledge is central for developing a better teaching rather than treating these as separate bodies of knowledge.

The stages finalized by the writer to develop the strategy based on TPACK are : Selection and formation of components of TPACK and Design and Development of TPACK based strategy.

Stage I : The selection and formation of TPACK components consists of the following processes :

- Selection of the Content : In this step the teacher selects the content and analyzes the selected content. This is important to help students to achieve the learning goal.

- Selection of Pedagogy : In this step the teacher selects different pedagogical strategies for the transaction of the selected content matter, students' assessment and classroom management. The selection of 'pedagogy' depends on the nature of the selected 'content'. The teacher can adopt inquiry based instruction, demonstration, experimentation, brain storming, think pair share, cooperative learning, independent work, etc., during the transaction of the selected topics.

- Selection of Technology : In this step the teacher may identify various technologies which may suit for lesson transaction. Before that the teacher has to consider the factors such as the need of the students, availability of the particular technology and facilities, etc. Technology may include the use of smart phone, laptop, projector, digital camera, Wi-Fi connection, computer 
simulation, power point presentation, Youtube, animations, learning applications, SAMAGRA resources, etc.

- Formation of PCK : In this step, the will recognize a particular pedagogy for teaching a particular content. The teacher will analyze the selected topic first and finds different ways to represent it and prepare teaching materials for alternative topics and choose the most suitable one.

- Formation of TCK : In this step, the teacher need to understand which specific technologies are best suited for teaching the selected content. Then the teacher will integrate the selected 'content' with most suitable 'technology'.

- Formation of TPK : In this step, the teacher applies the knowledge of how teaching and learning can change when certain technologies are used in particular ways in the classroom. The teacher will combine the selected technologies which supports the selected pedagogical techniques for each topic.

- Formation of TPACK : In this step, the teacher connects the selected 'content' with proper 'pedagogical' techniques and integrates it with most be fitting technologies to teach the selected topic in a constructive and fruitful manner.

Figure - 3: Process in TPACK Formation

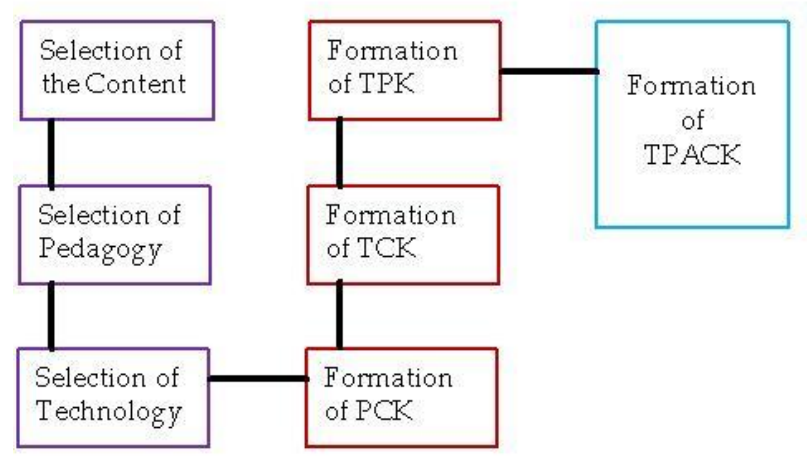

Stage II : The design and development of TPACK based strategy consists of five major phases :
Orientation Phase, Knowledge Acquisition Phase, Attainment Assessing Phase, Reviewing Phase, and Enrichment Phase.

Figure - 4: Phases of TPACK Based Strategy

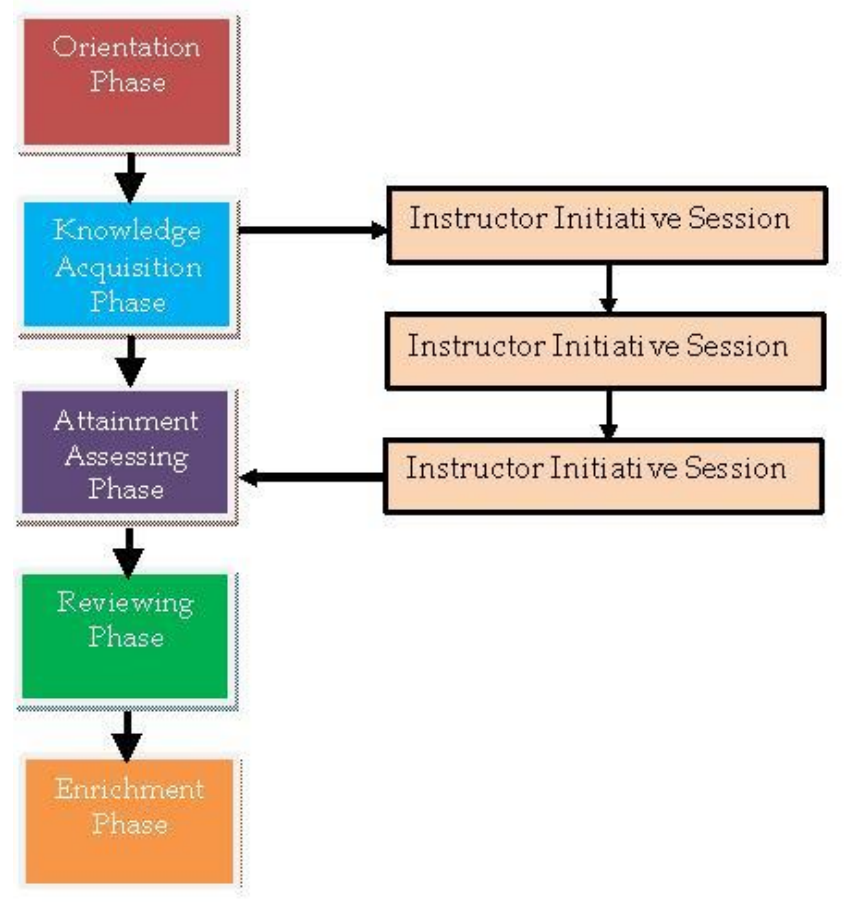

However, the present article will focus on Phase II : Knowledge Acquisition Phase for discussion purpose. Knowledge acquisition phase is the core phase in the TPACK strategy. It consists of three session.

i. Instructor initiative session : In this session the teacher introduces a new content to the students with the help of prepared TPACK based tools or activities. The delivery of the content shall be in the form of a video, animation, image, power point presentation, etc. Then the teacher will describe and assign prepared TPACK based activities which students should do.

ii. Participant collaborative session : In this session students will construct knowledge in accordance with their assigned activities in a collaborative manner. The teacher shall practice the inquiry based learning, problem solving method, group discussion, experimentation, think pair share, 
brainstorming games, etc., for teaching various topics.

iii. Instructor - participant collaboration session : In this session, the students will present their constructed knowledge before the teacher and discuss the experiences and outcomes. The teacher will make consolidations and give clarifications related to the discussed topic.

\section{IMPLICATIONS}

TPACK based strategy incorporates the growing demand for the use of technology in the classroom as well as continuing the focus on the 'content' and 'how to teach' it. It is very important that the teacher to be completely up to date and informed with the present curriculum and the latest technologies which can effectively incorporate it into their lessons for meaningful learning. Today, students are able to work better through technology. By adding 'technology' component to 'pedagogical' component makes the students more engaged in their learning and provide more meaningful learning experiences.

A review of research studies on TPACK based strategy clearly indicates that, teaching through this mode reduces students' academic stress, enhances academic achievement and improves retention power among students. This strategy is equally beneficial to develop positive attitude towards academic pursuits among students. Further, the collaborative and inquiry based learning methods involved in the TPACK based strategy shall improve co-operation among students and provide an opportunity for student centered learning. Students with various mental abilities are benefitted by different technology modes like videos, audios, ppts, Wi-fi, activities etc.

Since this strategy is highly effective in teaching engineering subjects, the curriculum planners shall take this into the account which preparing instructional materials and learning strategies for engineering students. This strategy could be included in the engineering curriculum and necessary training in this strategy should be given to teachers. Seminars, workshops, FIP, in-service courses, etc., may be considered for in-service teachers to train them in TPACK strategy.

\section{REFERENCES}

[1]. Archambault, L. M., and Barnett, J. H. (2010). Revisiting Technological Pedagogical Content Knowledge : Exploring the TPACK Framework. Computer and Education, 55(4), 1656-1662.

[2]. Habibi, A., Yusop, F. D., and Razak, R. A. (2020). The Role of TPACK in Affecting Preservice Language Teachers' ICT Integration during Teaching Practices : Indonesian Context. Education and Information Technologies, 25(3), 1929-1949.

[3]. Ilmi, A. M., and Sunarno, W. (2020). Development of TPACK based Physics Learning Media to Improve HOTS and Scientific Attitude. Journal of Physics : Conference Series, 1440(1), IOP Publishing.

[4]. Kabakci Yurdakal, I., and Coklar, A. N. (2014). Modelling Pre-service Teachers TPACK Competencies based on ICT Usage. Journal of Computer Assisted Learning, 30(4), 363-376.

[5]. Koehler, M. J., and Mishra, P. (2005). Teachers Learning Technology by Design. Journal of Computing in Teacher Education, 21(3), 94102.

[6]. Koehler, M. J., and Mishra, P. (2005). What Happens when Teachers Design Educational Technology ? The Development of Technological Pedagogical Content Knowledge. Journal of Educational Computing Research, 32(2), 131-152.

[7]. Koehler, M. J., and Mishra, P. (2009). What is Technological Pedagogical Content Knowledge

? Contemporary Issues in Technology and Teacher Education. CITE Journal, 9(1), 60-70. 
[8]. Koehler, M. J., Mishra, P., and Cain, W. (2013). What is Technological Pedagogical Content Knowledge (TPACK) Journal of Education, 193(3), 13-19.

[9]. Koehler, M. J., Mishra, P., and Yahya, K. (2007). Tracing the Development of Teacher Knowledge in a Design Seminar : Integrating Content, Pedagogy and Technology. Computers and Education, 49(3), 740-762.

[10]. Mishra, P. (2019). Considering Contextual Knowledge : The TPACK Diagram Gets an Upgrade. Journal of Digital Learning in Teacher Education, 35(2), 76-78.

[11]. Mishra, P., and Koehler, M. J. (2006). Technological Pedagogical Content Knowledge : A Framework for Teacher Education. Teachers College Record, 108(6), 1017-1054.

[12]. Mishra, P., (2018) Revised Version of TPACK Image. Retrieved from https : // punyamishra.com/2018/09.10/the -tpackdiagram-gets-an-upgrade.

[13]. Shulman, L. S. (1986). Those Who Understand : Knowledge Growth in Teaching. Educational Researcher, 15(2).

[14]. Sickle, J. L. (2016) TPACK Development in Science Teacher Preparation : A Case Study in Queensland, Australia (Doctoral Dissertation, Ohio University).

[15]. Thompson, A., and Mishra, P. (2007-08) Breaking News : TPCK becomes TPACK ! Journal of Computing in Teacher Education, 24(2), 3864.

[16]. Vijayan, V. (2019). Technological Pedagogical Content Knowledge Strategies for Enhancing Mathematical Ability of Secondary School Students. Central University of Kerala. Retrieved from https://shodhganga.inflibnet.ac. in/handle/10603/304706.

[17]. Voogt, J., Fisser, P., Tondeur, J., and Van Braak, J. (2016). Using Theoretical Perspectives in Developing an Understanding of TPACK. Handbook of Technological Pedagogical
Content Knowledge (TPACK) for Educators. (2), 31-51.

[18]. Yeh, Y. F., Hsu, Y. S., Wu, H. K., Hwang, F. K., and Lin, T. C. (2014). Developing and Validating Technological Pedagogical Content Knowledge - Practice (TPACK - Practical) through the Delphi Survey Technique. British Journal of Educational Technology, 45(4), 707722.

[19]. Zhang, S., Liu, Q., and Cai, Z. (2019). Exploring Primary School Teachers' Technological Pedagogical Content Knowledge (TPACK) in Online Collaborative Discourse : An Epistemic Network Analysis. British Journal of Educational Technology, 50(6), 3437-3455. https://doi.org/10. 1111/bjet.12751.

\section{Cite this article as :}

H. M. Naveen, "Content and Technology Based Pedagogy of Enriching Knowledge and Thinking Skills among Engineering Graduates", International Journal of Scientific Research in Computer Science, Engineering and Information Technology (IJSRCSEIT), ISSN : 2456-3307, Volume 7 Issue 5, pp. 28-34, September-October 2021. Journal URL : https://ijsrcseit.com/CSEIT217516 